\title{
Minimally Invasive Subaxial Cervical Pedicle Screw Placement with Routine Fluoroscopy: Cadaveric Feasibility Study and Report of 6 Clinical Cases
}

\author{
Umesh Srikantha ${ }^{1}$, Parichay J Perikal ${ }^{2}$, Akshay Hari ${ }^{1}$, Yadhu K Lokanath ${ }^{1}$, Nirmala Subramaniam ${ }^{1}$, \\ Aniruddha T Jagannatha ${ }^{3}$, Ravi G Varma ${ }^{1}$ \\ ${ }^{1}$ Department of Neurosurgery, Aster CMI Hospital, Bengaluru, India \\ ${ }^{2}$ Department of Neurosurgery, Ramaiah Medical College, Bengaluru, India \\ ${ }^{3}$ Department of Neurosurgery, Vikram Hospital, Bengaluru, India
}

Received: October 4, 2021

Revised: January 20, 2022

Accepted: January 23, 2022

Corresponding Author:

Umesh Srikantha, MS

Department of Neurosurgery, Aster

CMI Hospital, 43/2 New Airport

Road, NH-7, Outer Ring Rd, Sahakar

Nagar, Bengaluru, Karnataka

560092, India

Tel: +91-80-43420251

E-mail: umeshsrikantha@gmail.com
Objective: Conventional cervical pedicle screw insertion necessitates extensive paraspinal muscle dissection and retraction in order to achieve the lateral to medial angulation needed to achieve the optimal screw trajectory. Minimally invasive transmuscular approach can comfortably achieve this angulation without significant injury to the midline structures and its musculo-ligamentous attachments.

Methods: Minimally invasive cervical pedicle screws were inserted in 4 fresh frozen cadaveric specimens. Pre-procedure and post-procedure CT scans were done to assess the pedicle dimensions, suitability for screw insertion and integrity of the screws. The same technique was applied in a clinical cohort of six cases - 3 cases of traumatic subluxation; one case of traumatic vertebral fracture and 2 cases of infective facet destruction (Koch's).

Results: Among the 38 screws in the cadaver specimens, a total of 11 screws (28.9\%) had breached the pedicle wall(Lateral wall breach-9; Medial wall breach-2). Of the 9 screws $(23.6 \%)$ that had a lateral breach into the vertebral canal, 4 (10.5\%) each had Grade Ila breach and one (2.6\%) had Grade III breach. Among the 22 screws inserted in the clinical cohort of 6 cases, 4 screws $(18.1 \%)$ had breached the pedicle wall. All the identified breaches were in the lateral wall(Grade Ila - 3; Grade IIb-1; Grade III-nil).

Conclusion: Minimally invasive subaxial pedicle screw insertion provides robust posterior cervical fixation, either in isolation or as an adjunct to anterior surgery, in cases where a direct posterior decompression is not warranted. It is a safe and effective approach which minimizes inju$r y$ to the paraspinal structures and midline attachments.

Key Words: Cervical pedicle screw, Minimally invasive, Posterior cervical fixation, Percutaneous cervical fixation 


\section{INTRODUCTION}

Among the numerous techniques advocated for the stabilization of cervical spine, pedicle screws offer the greatest biomechanical stability [1-3]. However, placing cervical pedicle screws is technically demanding due to a narrow pedicle, significant variation in anatomy and hence, higher chances of pedicle wall perforation resulting in injury to adjacent important neurovascular structures $[4,5]$.

Another concern that is less frequently raised is the exposure required to access the lateral entry point and achieve a steep medial angulation required for proper positioning of these screws [1,2]. Several reports suggest that such extensive muscle dissection and retraction causes disruption of the posterior musculo-ligamentous tension band resulting in impaired post-operative neck muscle function and may be responsible for persistent neck discomfort $[6,7]$.

Minimally invasive muscle splitting approaches, introduced for the lumbar spine, have the potential to significantly reduce muscle injury and preserve the posterior tension band [8]. Their superiority in minimizing blood loss, reducing the duration of hospital stay, enabling earlier return to work and improving functional outcomes as compared to conventional procedures has been shown in several studies $[9,10]$. Recently, several reports of extension of this technique to the cervical spine have appeared in the literature and have shown promising outcomes [11-13].

The present study elaborates technique and results of placing minimally invasive cervical pedicle screws in four cadaveric specimens and subsequently in six clinical cases.

\section{MATERIALS AND METHODS}

\section{Cadaveric Specimens}

Four fresh frozen cadavers with intact cervical spine and good visualization of the bony anatomy on fluoroscopy were selected for the study. Pre-operative CT scan with axial, saggital and coronal reconstruction was done in all the cadavers to note the dimensions and integrity of $\mathrm{C} 3$ to $\mathrm{C} 7$ pedicles and their practicality to accept a standard $3.5 \mathrm{~mm}$ screw. Using the minimal access technique described below, bilateral C3 to C7 pedicle screws were placed in all the cadavers. Post- procedural CT scans was done in all the cadavers with axial, saggital and coronal reconstructions to assess the position and integrity of the screws. The following parameters were noted on the CT scans:
- Transverse pedicle angle (pre-procedure CT) (Figure 1): measured as the angle between the long axis of the pedicle and the vertical plane (vertical line bisecting the vertebral body)

- Transverse screw angle (post-procedure CT): measured as the angle between the long axis of the screw and the vertical plane

- Pedicle wall breach (post-procedure CT) - Pedicle screw integrity was assessed based on the percentage of perforation and involvement of neurovascular structures

- Grade I - within pedicle; No breach

- Grade IIa $-<25 \%$ and no contact with neurovascular structures

- Grade IIb - <25\% and contact with neurovascular structures - Grade III - >25\% of screw diameter breached the pedicle wall In addition, the direction of breach, whether lateral or medial was also noted.

- Anterior/Lateral v. body breach (post-procedure CT)

\section{1) Surgical Technique}

Cadaveric specimens were placed prone on bolsters and head fixed with a makeshift frame. Anteroposterior and lateral fluoroscopy was done to ensure clear visibility of the cervical spine for the procedure. A linear vertical incision was made on either side, 3.0 to $3.5 \mathrm{~cm}$ off the midline, extending vertically from C3-4 interspace lower down to C6 vertebral body on the lateral fluoroscopy image. The incision roughly corresponded to a line approximately $0.5-1 \mathrm{~cm}$ lateral to the lateral border of the lateral mass on an anteroposterior fluoroscopy image. The incision was deepened in layers and dissection done with

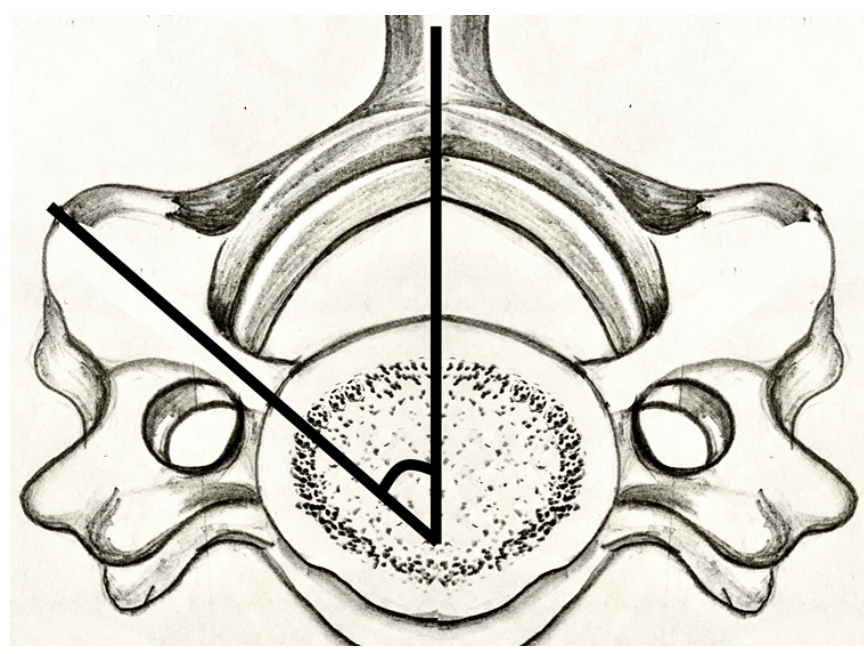

Figure 1. Criteria used to measure transverse pedicle angle. 
finger and blunt instruments to create a plane all the way down to reach the dorsal surface of lateral mass. Sequential dilatation was done to finally dock an expandable $22 \mathrm{~mm}$ tubular retractor (Quadrant system, Medtronic Sofamor Danek, Memphis, TN, USA) roughly at the level of C4-5. The vertical blades of the retractor were expanded and further muscle dissection done to expose the dorsolateral part of lateral masses from C3 to C6, and approximate pedicle screw entry points were identified in the upper lateral quadrant of the lateral mass in line with the waist of the articular pillar. The retractor had to be angulated inferiorly in order to visualize the lateral mass of $\mathrm{C} 7$ and pedicle screw entry point. A high speed drill was used to drill off the cortex horizontally (as described in the key slot technique) [14], and pedicle was cannulated with a $1 \mathrm{~mm}$ bone curette. The direction of the curette was predominantly turned medially, observing that the medial cortex of the pedicle was thicker [15] and difficult to violate as compared to the lateral wall, which was thinner and most liable to be breached during pedicle screw placement. Once the pedicle was cannulated, the track was drilled with a $2.7 \mathrm{~mm}$ hand held drill. The walls of pedicle were probed for any breach and an appropriate length $3.5 \mathrm{~mm}$ screw was inserted into the same track. Similar steps were followed in inserting pedicle screws from C3 to C7, sequentially first on one side and then on the other (Figure 2).

\section{RESULTS}

\section{Cadaveric Specimens}

Of the 40 pedicles assessed on pre-procedural CT of 4 fresh frozen cadavers (C3-C7, Bilateral, 10 each per cadaver), 2 of the pedicels were sclerosed and very narrow with transverse diameter $<2.5 \mathrm{~mm}$ and were not selected for screw insertion. Minimally invasive cervical pedicle screws could be successfully inserted in the remaining 38 pedicles, which were analyzed on post-procedural CT. The mean transverse pedicle angle was $45.6^{\circ}$ at $\mathrm{C} 3,47.7^{\circ}$ at $\mathrm{C} 4,46.1^{\circ}$ at $\mathrm{C} 5,38.6^{\circ}$ at $\mathrm{C} 6$ and $32.7^{\circ}$ at $\mathrm{C} 7$.

Among the 38 screws, a total of 11 screws (28.9\%) had breached the pedicle wall (Lateral wall breach - 9; Medial wall breach - 2). Of the 9 screws $(23.6 \%)$ that had a lateral breach into the vertebral canal, 4 (10.5\%) each had Grade IIa breach and one (2.6\%) had Grade III breach (Figure 3). Three of the lateral breaches were at C3, 4 at C4 and 2 at C5. Apart from these, 2 screws had a medial breach, one Grade IIa and one grade IIb. Both of these were at C3. All the screws at C6 and C7 were intact with no pedicle wall violation in any direction.

Correlation was also observed between mean transverse
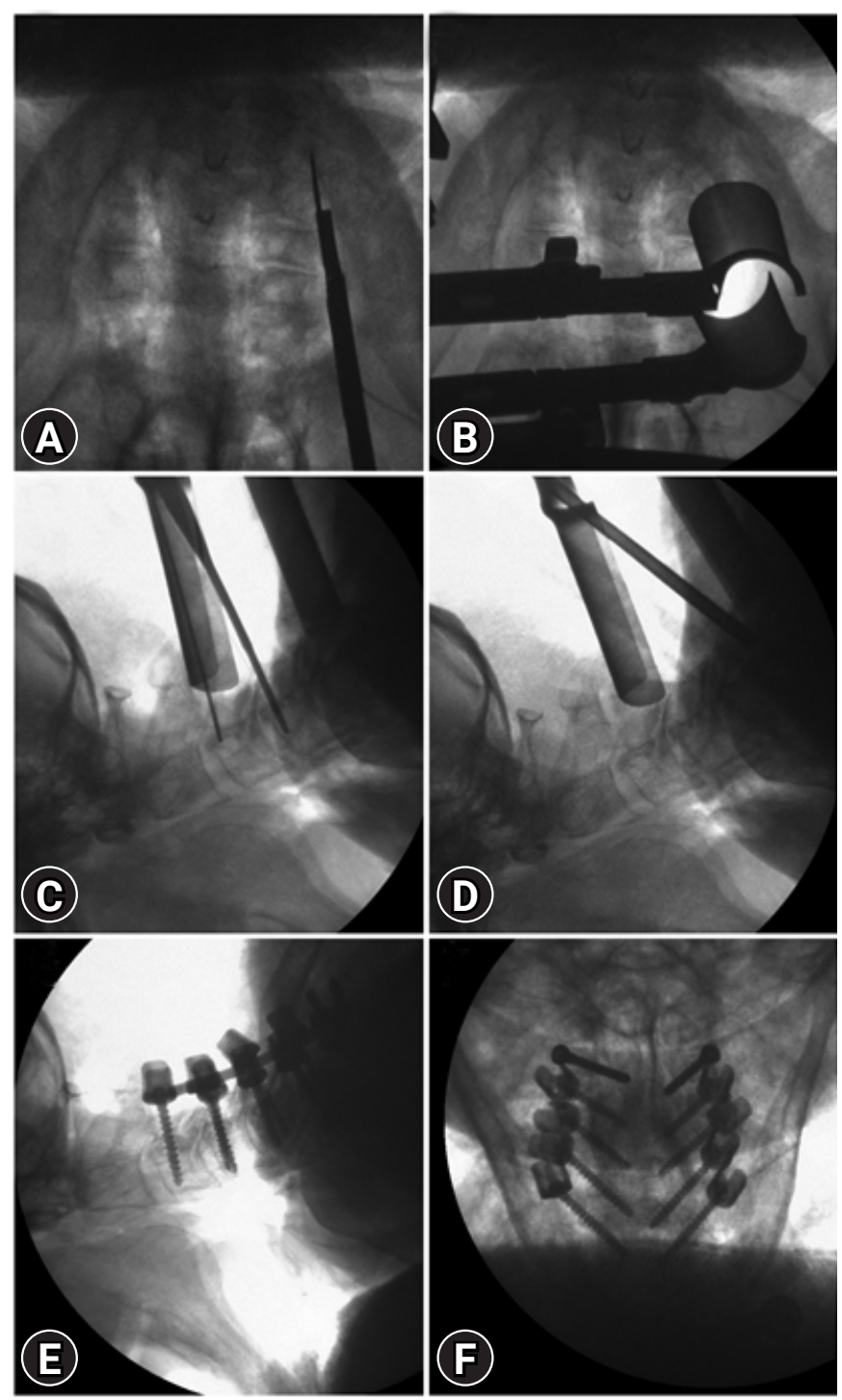

Figure 2. Representative images for pedicle screw insertion in one of the cadavers. (A) Marking the incision approximately $1 \mathrm{~cm}$ lateral to the lateral border of lateral mass on AP fluoroscopy. (B) Positioning the expandable tubular retractor. (C) Making drill holes with a $1 \mathrm{~mm}$ curette (C4), (D) angulating the tube inferiorly to access C6 and C7. (E) Lateral and (F) AP fluoroscopy after placing bilateral pedicle screws from $\mathrm{C} 3$ to $\mathrm{C} 7$.

screw angle and direction of pedicle breach. The mean transverse screw angle in the subset of pedicle screws with no breach was $34.1^{\circ}$ whereas it was $22.1^{\circ}$ in screws that had lateral breach and $43.6^{\circ}$ in those that had medial breach.

Six screws (15.7\%) had lateral vertebral body breach. Understandably, all these cases had lateral pedicle wall breach as well. None of the screws had an anterior vertebral body breach. 

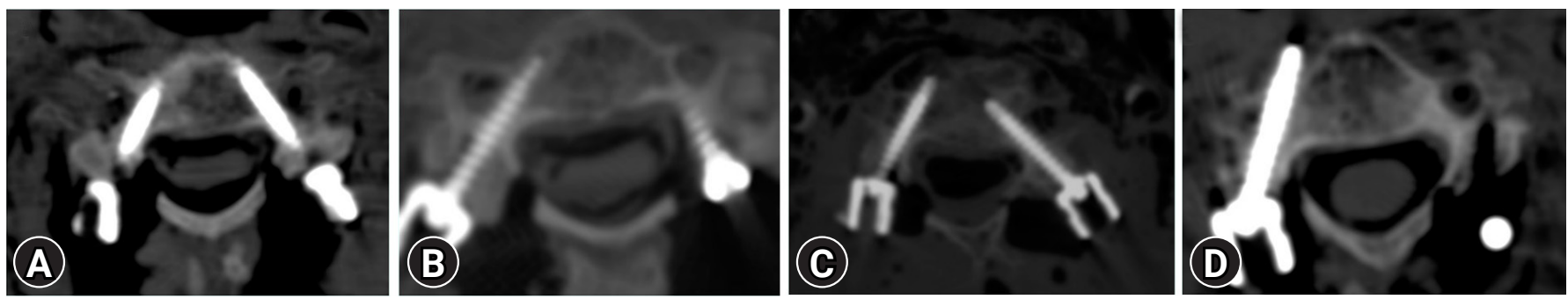

Figure 3. Representative post-procedural CT scans in cadaver specimens showing the pedicle screw integrity. (A) Bilateral pedicle screws intact. (B) Gr. Ila breach in the right pedicle screw. (C) Gr Ilb breach in the right pedicle screw with correctly placed screw on left side. (D) Right screw showing Gr. III lateral wall breach as well as lateral vertebral body breach.

Table 1. Summary of clinical cases

\begin{tabular}{|c|c|c|c|c|c|c|c|}
\hline No. & $\begin{array}{l}\text { Age/ } \\
\text { sex }\end{array}$ & Final diagnosis & Clinical & Procedure & $\begin{array}{c}\text { No. of screws } \\
\text { included for study }\end{array}$ & Integrity of screw & $\mathrm{f} / \mathrm{u}$ and status \\
\hline 1 & $55 / F$ & $\begin{array}{l}\text { C3 lateral mass Koch's } \\
\text { with destruction }\end{array}$ & $\begin{array}{l}\text { Severe neck pain; } \\
\text { No FND }\end{array}$ & $\begin{array}{l}\text { Tube-assisted decompression; } \\
\text { C2-C4 MIS pedicle screw } \\
\text { fixation }\end{array}$ & $2(b / / C 4)$ & $\begin{array}{l}\text { Gr lla, unilateral, } \\
\text { lateral (CT) }\end{array}$ & $\begin{array}{l}20 \text { months, no FND, } \\
\text { completed ATT }\end{array}$ \\
\hline 2 & $22 / \mathrm{M}$ & C5-6 subluxation & ASIA E & C5-6 MIS pedicle screw fixation & 4 & $\begin{array}{l}\text { No breach (X-ray/ } \\
\text { intra-op) }\end{array}$ & 8 months, back to work \\
\hline 3 & $24 / F$ & $\begin{array}{l}\text { C5-6 subluxation } \\
\text { (Fig. 4) }\end{array}$ & ASIAE & C5-6 MIS pedicle screw fixation & 4 & $\begin{array}{l}\text { Gr lla, unilateral, } \\
\text { lateral (CT) }\end{array}$ & $\begin{array}{l}12 \text { months, back to } \\
\text { work }\end{array}$ \\
\hline 4 & $38 / \mathrm{F}$ & $\begin{array}{l}\text { C3 lateral mass koch's } \\
\text { with destruction } \\
\text { (Fig. 5) }\end{array}$ & $\begin{array}{l}\text { Severe neck pain; } \\
\text { No FND }\end{array}$ & $\begin{array}{l}\text { Tube-assisted decompression; } \\
\text { C2-C4 MIS pedicle screw } \\
\text { fixation }\end{array}$ & $2(b / / c 4)$ & $\begin{array}{l}\text { No breach (X-ray/ } \\
\text { intra-op) }\end{array}$ & $\begin{array}{l}18 \text { months, no FND; } \\
\text { Completed ATT }\end{array}$ \\
\hline 5 & $47 / \mathrm{M}$ & C6-7 subluxation & ASIA D & C6-7 MIS pedicle screw fixation & 4 & No breach (CT) & 4 months, no FND \\
\hline & $34 / \mathrm{M}$ & $\begin{array}{l}\mathrm{C} 5,6 \text { fracture with } \mathrm{PLC} \\
\text { injury }\end{array}$ & ASIA D & $\begin{array}{l}\text { C4,5-C7 MIS pedicle screw } \\
\text { fixation }\end{array}$ & 6 & Gr Ilb (1) & $\begin{array}{l}2 \text { years, no FND, back } \\
\text { to work }\end{array}$ \\
\hline & & & & & & Gr lla (1) (CT) & \\
\hline
\end{tabular}

F: female, FND: focal neurological deficits, b/l: bilateral, CT: computed tomography, Gr: grade, PLC: posterior ligamentous complex, f/u: follow-up, AT: anti-tubercular treatment.

\section{Clinical Cases}

A total of 22 subaxial pedicle screws were inserted among 6 cases that underwent free hand or 2D fluoro-guided minimally invasive pedicle screw stabilization for various pathologies between 2014 to 2017. The details of the clinical cases are enumerated in Table 1 (Figure 4, 5). The senior author (US) has shifted to 3D-navigation guided minimally invasive cervical pedicle screw stabilization after 2017 (not discussed here).

None of the clinical cases had any approach/wound related complications. All patients were mobilized on first post-operative day with a hard-cervical collar, which was kept for 3 weeks. Post-operative CT scan to assess screw accuracy could be done in 4 cases ( 16 screws). The results in other two patients (6 screws) were tabulated solely on the basis of post-op X-ray and intra-op probing. Of the 22 screws, 4 screws (18.1\%) had breached the pedicle wall. All the identified breaches were in the lateral wall (Grade IIa - 3; Grade IIb - 1; Grade III - nil). None of them had any obvious vertebral artery related compli- cations. All the breaches were identified on CT scans. All patients had uneventful post-op recovery and were having good functional status at the time of their last follow-up.

\section{DISCUSSION}

Cervical Pedicle screw fixation, first described by Abumi et al. [1] in 1994, has been shown to be the strongest means of fixation in the subaxial cervical spine $[3,16]$. They have been used in the treatment of various cervical pathologies including traumatic subluxations or fracture $[1,17]$, deformity $[18,19]$ and tumors [20], especially in presence of co-existing severe osteoporosis [21]. In the present study, we assessed the feasibility of minimally invasive subaxial cervical pedicle screw placement on a subset of 4 cadaveric specimens ( 4 specimens; 38 screws) before applying the technique in the clinical setting (6 cases; 22 screws). The senior author (US) had followed a similar protocol for Minimally invasive atlanto-axial fixation as well [22]. Though cervical pedicle screw insertion using lateral stab in- 

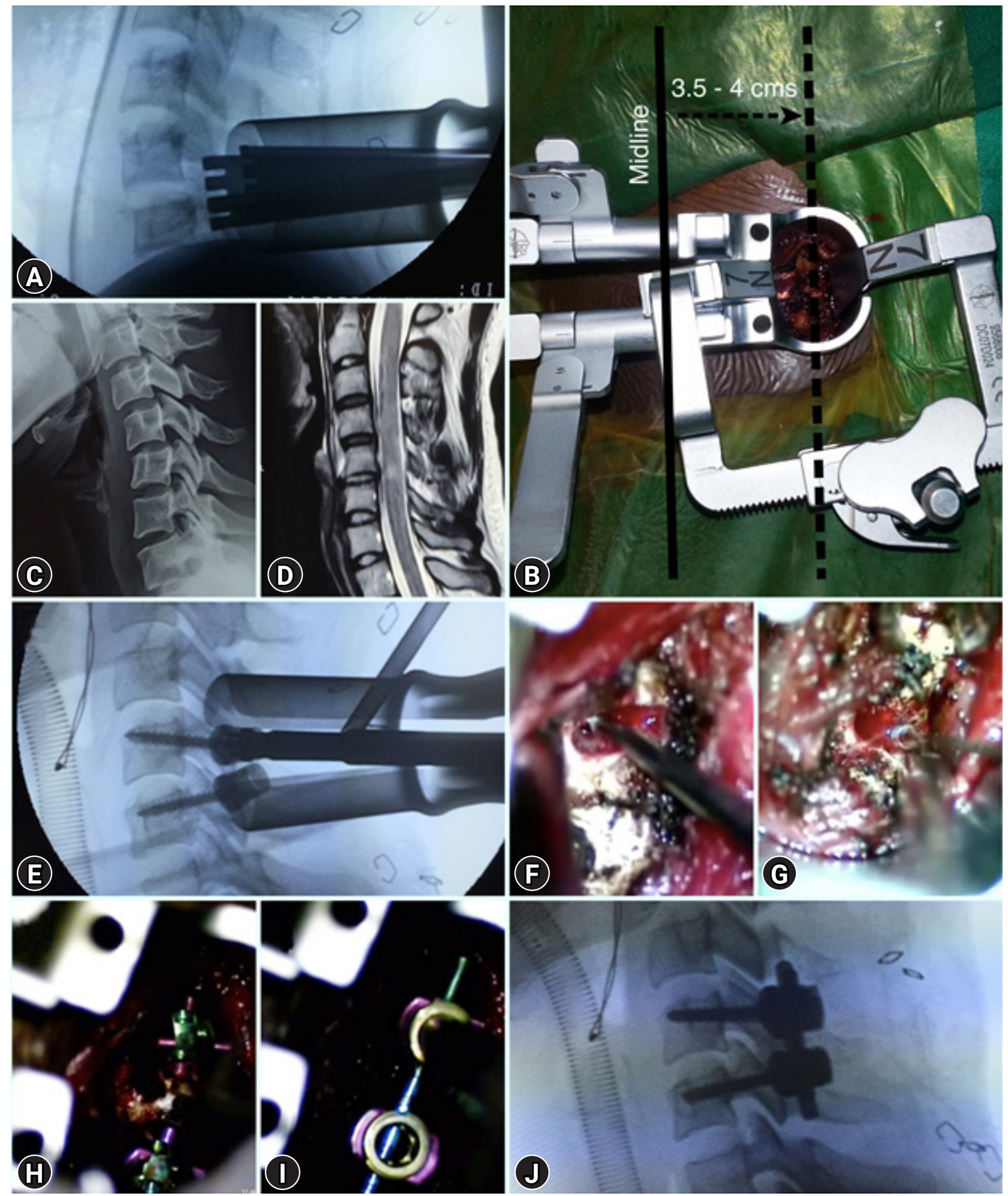

Figure 4. Illustrative images of minimally invasive pedicle screw stabilization in a case of C5-6 Gr1 subluxation. (C, D) Pre-operative lateral X-ray and T2W sagittal MRI image showing subluxation at C5-6 with intrinsic cord signal changes. (A) Intra-operative lateral fluoroscopy image showing tubular retractor in place. (B) Intra-operative image showing the tubular retractors in place and the incision of approach approximately $3.5-4.0 \mathrm{~cm}$ lateral to the midline. (E) Lateral Fluoroscopy image showing placement of pedicle screws. $(F, G)$ Intra-operative microscope views showing pedicle being cannulated with a $1 \mathrm{~mm}$ curette (angled medially) (F) and later being probed (G) to identify any breach. $(H, I)$ Intra-operative microscope views showing both screws after placement $(H)$ and after rod and Innie screw insertion (I). (J) Final intra-operative image after bilateral pedicle screw stabilization. 

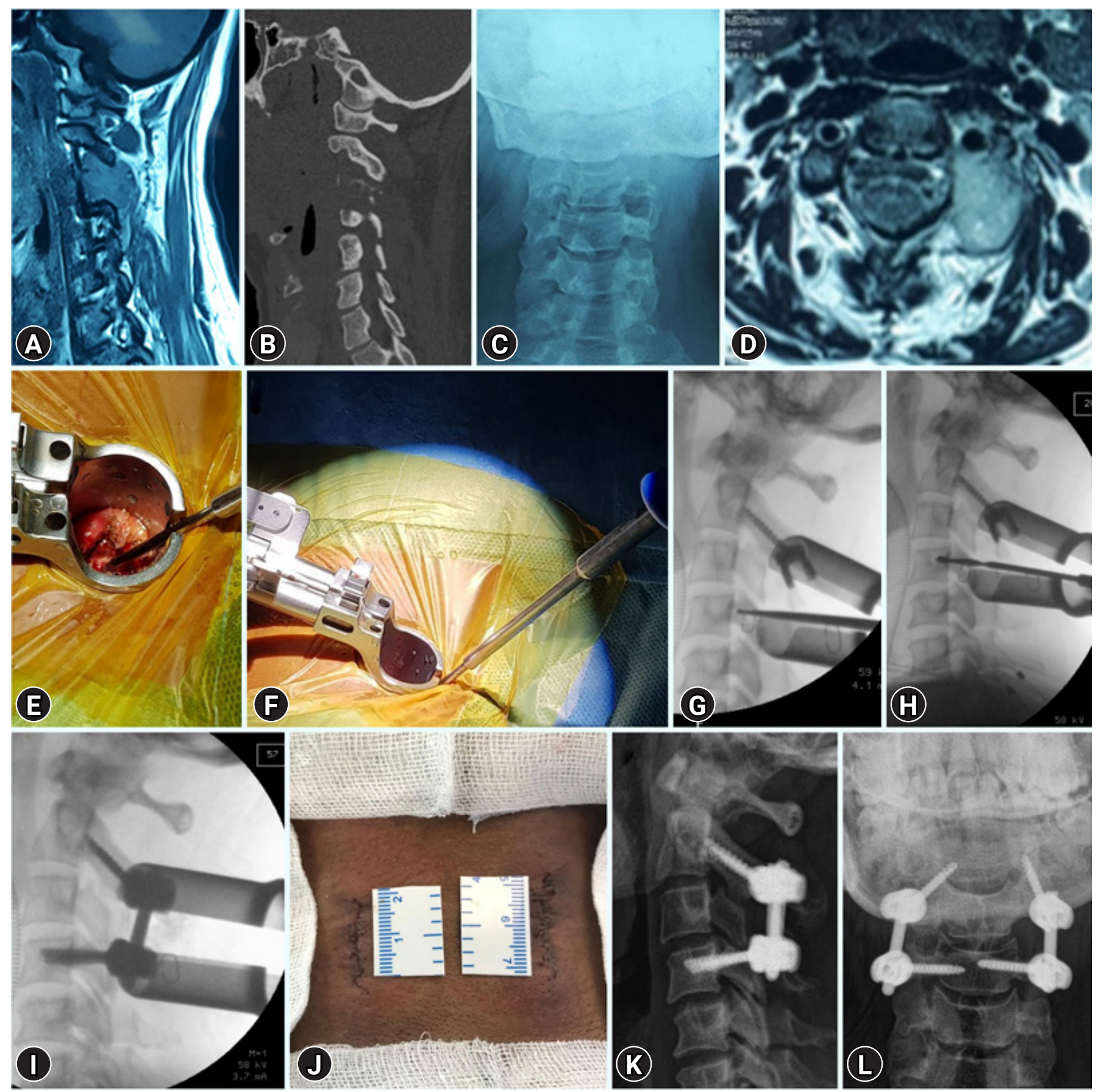

Figure 5. Illustrative images of minimally invasive pedicle screw stabilization in a case of C3 lateral mass Koch's with destruction. (A-D) Pre-operative images showing near-total destruction of the left C3 lateral mass visible both in CT (B) and AP fluoroscopy image (C) by a lesion that is isointense on T1W (A) and hyperintense on T2W (D) MRI image with no intracanalicular component. (E, F) Intra-operative photographs showing placement of tubular retractor (E) and lateral to medial angulation achieved for placing pedicle screw (F). (G, H) Intra-operative lateral fluoroscopy images showing insertion of bilateral C4 pedicle screw sequentially with a $1 \mathrm{~mm}$ curette (G) and a $2.7 \mathrm{~mm}$ hand held drill guide (H). (I) Final intra-operative fluoroscopy image after placing bilateral C2-C4 pedicle screws and rods. (J) Image showing bilateral 2-2.5 cm wounds after closure. $(K, L)$ Lateral $(K)$ and AP $(L) X$-rays done at 6 months follow-up.

cision was done previously, minimally invasive approach with use of a tubular retractor and free hand placement of cervical pedicle screw was first attempted by Lee and Park [23].
The reported overall rates of cervical pedicle screw breach in the literature range form $9 \%-30 \%$ overall with $4 \%-12 \%$ incidence of major (grade IIb and III) pedicle wall breaches, that 
can potentially injure the neurovascular structures [24-26]. The rates are similar in our cadaver study as well, with an overall pedicle breach rate of $28.9 \%$ and major (grade IIb and III) breach rate of $13.1 \%$. In our clinical series of 22 screws, the overall breach rate was $18.1 \%$ with one screw (4.5\%) having a major breach (Grade IIb). Several other series on minimally invasive cervical pedicle screw placement have shown pedicle breach rates that are similar or better to open series $[27,28]$. Komatsubara et al. [29] reported lesser incidence of screw perforation in the minimally invasive group, owing to a better transverse pedicle angle, which reduces the incidence of lateral pedicle wall breaches as compared to an open technique. Koakutsu et al. [30] did not have any pedicle breach in 29 screws placed by a novel minimally invasive technique. Several other isolated reports of successful minimally invasive cervical pedicle screw placement are also present [23,31].

Minimally invasive cervical pedicle screw insertion has the obvious advantages of minimizing soft tissue dissection and paraspinal injury as compared to an open approach, an extension of the principle that have yielded good results in percutaneous thoraco-lumbar pedicle screw fixation $[32,33]$. The significant lateral to medial angulation needed for placing cervical pedicle screws necessitates an extensive lateral paraspinal exposure and retraction. In cases where the soft tissue impedance is significantly higher, a separate lateral stab incision has also been recommended [34] to aid in achieving the lateral to medial trajectory, minimize soft tissue injury and prevent lateral pedicle wall breaches. Minimally invasive cervical pedicle screw insertion obviates the need for midline dissection, paraspinal muscle retraction and by creating a transmuscular route, comfortably achieves the lateral to medial screw angulation required $[27,29,35]$. In our cadaver study, the mean transverse screw angle in those with lateral pedicle wall breach was $22.1^{\circ}$, lower than the mean transverse angle in screws with no breach $\left(34.1^{\circ}\right)$. The more vertical angulation ideally should have been avoided with a minimally invasive approach. The incidence of lateral wall breach in our clinical series has improved, owing partially at least to the correction of the lateral to medial angulation.

Studies that compare open vs minimally invasive posterior laminoforaminotomy (comparatively a much simpler exposure in open surgeries as compared to open cervical pedicle screw insertion) have shown significant benefit and advantages for the minimally invasive approach $[36,37]$. It could hence be rationally hypothesized that minimally invasive cervical pedicle screw placement would yield better outcomes as compared to an open approach, as far as approach related morbidity is con- cerned. A Japanese study that compared outcomes in a small group of 12 open pedicle screw insertion and 6 cases of Minimally invasive pedicle screw insertion reported significantly reduced blood loss in the minimally invasive group [35]. To the best of our knowledge, there are no studies that have compared differences in approach related morbidity between open and minimally invasive subaxial pedicle screw insertion in a detailed manner, with biochemical and markers of tissue injury being assessed.

Minimally invasive cervical pedicle screw placement does have its limitations. In the absence of 3D navigation, it demands a certain degree of skill and expertise to place an already challenging subaxial cervical pedicle screw in a minimally invasive fashion. We have used this technique sparingly in simple cases with good pedicles, in patients who were neurologically well preserved. Reducible traumatic grade 1 subluxations with no disc prolapse or canal compromise are ideal for a standalone posterior stabilization and fusion. The 2 cases of lateral mass lesion (Koch's spine) without much of intra-canalicular component or cord compression presents an ideal case for a lateral approach, wherein the tubular retractor can be directly docked onto the area of pathology and achieve adequate decompression as well as fixation in the same sitting, at the same time obviating any injury to the intact midline structures and its musculo-ligamentous attachments. As expected, addressing any canalicular pathology and achieving cord decompression is difficult with this far lateral approach.

To summarize, minimally invasive subaxial pedicle screw insertion can be utilized in cases where a robust posterior fixation is required, either in isolation or as an adjunct to anterior surgery, in cases where a direct posterior canalicular or spinal cord decompression is not warranted. It is a safe and effective approach which minimizes injury to the paraspinal structures and midline attachments. A larger series and prospective comparison with conventional/open pedicle screw fixation are needed to conclusively establish its presumed clinical benefit.

\section{CONFLICT OF INTEREST}

No potential conflict of interest relevant to this article.

\section{REFERENCES}

\footnotetext{
1. Abumi K, Itoh H, Taneichi H, Kaneda K. Transpedicular screw fixation for traumatic lesions of the middle and lower cervical spine: description of the techniques and preliminary report. J Spinal Disord 1994;7:19-28.
} 
2. Karaikovic EE, Yingsakmongkol W, Gaines RW Jr. Accuracy of cervical pedicle screw placement using the funnel technique. Spine (Phila Pa 1976) 2001;26:2456-2462.

3. Jones EL, Heller JG, Silcox DH, Hutton WC. Cervical pedicle screws versus lateral mass screws. Anatomic feasibility and biomechanical comparison. Spine (Phila Pa 1976) 1997;22:977-982.

4. Karaikovic EE, Kunakornsawat S, Daubs MD, Madsen TW, Gaines RW Jr. Surgical anatomy of the cervical pedicles: landmarks for posterior cervical pedicle entrance localization. J Spinal Disord 2000;13:63-72.

5. Yukawa Y, Kato F, Ito K, Horie Y, Hida T, Nakashima H, et al. Placement and complications of cervical pedicle screws in 144 cervical trauma patients using pedicle axis view techniques by fluoroscope. Eur Spine J 2009;18:1293-1299.

6. Kotani Y, Abumi K, Ito M, Sudo H, Takahata M, Ohshima S, et al. Minimum 2-year outcome of cervical laminoplasty with deep extensor muscle-preserving approach: impact on cervical spine function and quality of life. Eur Spine J 2009;18:663671.

7. Shiraishi T, Kato M, Yato Y, Ueda S, Aoyama R, Yamane J, et al. New techniques for exposure of posterior cervical spine through intermuscular planes and their surgical application. Spine (Phila Pa 1976) 2012;37:E286-E296.

8. Rahman M, Summers LE, Richter B, Mimran RI, Jacob RP. Comparison of techniques for decompressive lumbar laminectomy: the minimally invasive versus the "classic" open approach. Minim Invasive Neurosurg 2008;51:100-105.

9. Fan S, Hu Z, Zhao F, Zhao X, Huang Y, Fang X. Multifidus muscle changes and clinical effects of one-level posterior lumbar interbody fusion: minimally invasive procedure versus conventional open approach. Eur Spine J 2010;19:316324.

10. Tian NF, Wu YS, Zhang XL, Xu HZ, Chi YL, Mao FM. Minimally invasive versus open transforaminal lumbar interbody fusion: a meta-analysis based on the current evidence. Eur Spine J 2013;22:1741-1749.

11. Santiago P, Fessler RG. Minimally invasive surgery for the management of cervical spondylosis. Neurosurgery 2007; 60:S160-S165.

12. Wang MY, Levi AD. Minimally invasive lateral mass screw fixation in the cervical spine: initial clinical experience with long-term follow-up. Neurosurgery 2006;58:907-912.

13. Celestre PC, Pazmiño PR, Mikhael MM, Wolf CF, Feldman LA, Lauryssen C, et al. Minimally invasive approaches to the cervical spine. Orthop Clin North Am 2012 43:137-147. x

14. Lee SH, Kim KT, Abumi K, Suk KS, Lee JH, Park KJ. Cervical pedicle screw placement using the "key slot technique": the feasibility and learning curve. J Spinal Disord Tech 2012; 25:415-421.

15. Reinhold M, Bach C, Audigé L, Bale R, Attal R, Blauth M, et al. Comparison of two novel fluoroscopy-based stereotactic methods for cervical pedicle screw placement and review of the literature. Eur Spine J 2008;17:564-575.

16. Kothe R, Rüther W, Schneider E, Linke B. Biomechanical analysis of transpedicular screw fixation in the subaxial cervical spine. Spine (Phila Pa 1976) 2004;29:1869-1875.

17. Liu B, Liu X, Shen X, Wang G, Chen Y. The "slide technique"-a novel free-hand method of subaxial cervical pedicle screw placement. BMC Musculoskelet Disord 2020;21:399.

18. Abumi K, Shono Y, Taneichi H, Ito M, Kaneda K. Correction of cervical kyphosis using pedicle screw fixation systems. Spine (Phila Pa 1976) 1999;24:2389-2396.

19. Rajasekaran S, Kanna PR, Shetty TA. Intra-operative computer navigation guided cervical pedicle screw insertion in thirty-three complex cervical spine deformities. J Craniovertebr Junction Spine 2010;1:38-43.

20. Oda I, Abumi K, Ito M, Kotani Y, Oya T, Hasegawa K, et al. Palliative spinal reconstruction using cervical pedicle screws for metastatic lesions of the spine: a retrospective analysis of 32 cases. Spine (Phila Pa 1976) 2006;31:1439-1444.

21. Abumi K, Kaneda K, Shono Y, Fujiya M. One-stage posterior decompression and reconstruction of the cervical spine by using pedicle screw fixation systems. J Neurosurg 1999;90(1 Suppl):19-26.

22. Srikantha U, Khanapure KS, Jagannatha AT, Joshi KC, Varma RG, Hegde AS. Minimally invasive atlantoaxial fusion: cadaveric study and report of 5 clinical cases. J Neurosurg Spine 2016;25:675-680.

23. Lee S, Park JH. Minimally invasive cervical pedicle screw placement with a freehand technique through the posterolateral approach using a tubular retractor: a technical note. Oper Neurosurg (Hagerstown) 2019;17:E166-E172.

24. Abumi K, Shono Y, Ito M, Taneichi H, Kotani Y, Kaneda K. Complications of pedicle screw fixation in reconstructive surgery of the cervical spine. Spine (Phila Pa 1976) 2000;25:962969.

25. Uehara M, Takahashi J, Ikegami S, Mukaiyama K, Kuraishi S, Shimizu M, et al. Screw perforation features in 129 consecutive patients performed computer-guided cervical pedicle screw insertion. Eur Spine J 2014;23:2189-2195.

26. Wang Y, Xie J, Yang Z, Zhao Z, Zhang Y, Li T, et al. Computed tomography assessment of lateral pedicle wall perforation by free-hand subaxial cervical pedicle screw placement. Arch 
Orthop Trauma Surg 2013;133:901-909.

27. Coric D, Rossi VJ, Peloza J, Kim PK, Adamson TE. Percutaneous, navigated minimally invasive posterior cervical pedicle screw fixation. Int J Spine Surg 2020;14:S14-S21.

28. Lang Z, Tian W, Yuan Q, He D, Yuan N, Sun Y. [Percutaneous minimally invasive pedicle screw fixation for cervical fracture using intraoperative three-dimensional fluoroscopy-based navigation]. Zhonghua Wai Ke Za Zhi 2015 53:752-756. Chinese

29. Komatsubara T, Tokioka T, Sugimoto Y, Ozaki T. Minimally invasive cervical pedicle screw fixation by a posterolateral approach for acute cervical injury. Clin Spine Surg 2017;30:466469.

30. Koakutsu T, Aizawa T, Itoi E. Accurate and minimally invasive cervical pedicle screw insertion procedure using the bone biopsy needle as drill guide. Spine Surg Relat Res 2020;4:358364.

31. Tanaka M, Fujiwara Y, Uotani K, Kadiri V, Yamauchi T. C-armfree minimally invasive cervical pedicle screw fixation (MICEPS): a technical note. Acta Med Okayama 2020;74:551556.

32. Grass R, Biewener A, Dickopf A, Rammelt S, Heineck J, Zwipp H. Perkutane dorsale versus offene Instrumentation bei Frakturen des thorakolumbalen Ubergangs. Eine vergleichende prospektive Untersuchung [Percutaneous dorsal versus open instrumentation for fractures of the thoracolumbar border. A comparative, prospective study]. Unfallchirurg 2006 109:297305. German

33. Lee JK, Jang JW, Kim TW, Kim TS, Kim SH, Moon SJ. Percutaneous short-segment pedicle screw placement without fusion in the treatment of thoracolumbar burst fractures: is it effective?: comparative study with open short-segment pedicle screw fixation with posterolateral fusion. Acta Neurochir (Wien) 2013 155:2305-2312. discussion 2312

34. Uehara M, Takahashi J, Hirabayashi H, Hashidate H, Ogihara N, Mukaiyama K, et al. Perforation rates of cervical pedicle screw insertion by disease and vertebral level. Open Orthop J 2010;4:142-146.

35. Sugimoto Y, Hayashi T, Tokioka T. Minimally invasive cervical pedicle screw fixation via the posterolateral approach for metastatic cervical spinal tumors. Spine Surg Relat Res 2017;1:218-221.

36. Clark JG, Abdullah KG, Steinmetz MP, Benzel EC, Mroz TE. Minimally invasive versus open cervical foraminotomy: a systematic review. Global Spine J 2011;1:9-14.

37. Subramanian N, Srikantha U, Jagannatha AT, Khanapure K, Varma RG, Hegde AS. Posterior cervical laminoforaminotomy: a comparative study between open vs minimally invasive approach. J Spinal Surg 2015;2:8-12. 